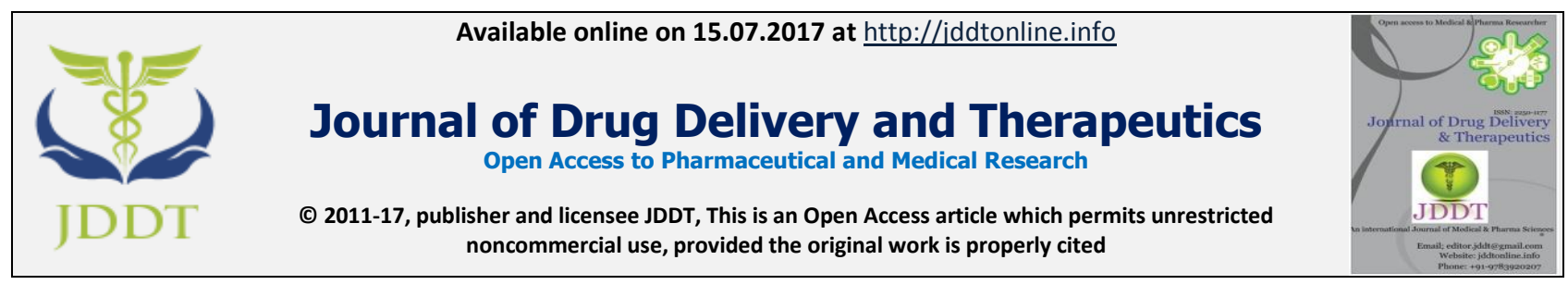

Open 2 Access

Research Article

\title{
OPTIMIZATION OF RIFAMYCIN B USING NOCARDIA MEDITERRANEA (ATCC 13865) BY FED BATCH MODE IN SHAKE FLASKS
}

\author{
Suneel Kumar Niranjan $^{1 *}$, Chandrul Kaushal ${ }^{1}$, S.K. Jain ${ }^{2}$ \\ ${ }^{1}$ Institute of pharmacy Shri Venkateshwara University, Gajraula, Uttar Pradesh, India \\ ${ }^{2}$ Institute of pharmacy, Bundelkhand University, Jhansi, Uttar Pradesh, India
}

\section{ABSTRACT}

The present study was carried out to evaluate the optimum Production of Rifamycin B by using fed- batch mode in the shake flask at the defenit level of different agitation and aeration rate, amongst different carbohydrate in the form of monoshacride. Amongst the various carbohydrate (Arabinose, Fructose, Galactose, Glucose, Glycerol, Maltose, Mannitol, Sorbitol, and Sucrose) sources maximum, the rifamycin $\left(578 \mu \mathrm{gml}^{-1}\right)$ with $10 \%$ glucose level was found as compared to control which was $\left(138 \pm 2.70 \mu \mathrm{gml}^{-1}\right)$. The environmental factors such as incubation temperature. The optimum temperature for maximum antibiotic production $\left(525 \mu \mathrm{gml}^{-1}\right)$ was found to be $29^{\circ} \mathrm{C}$, initial $\mathrm{pH}$, aeration and agitation rates were also optimized. The optimum rifamycin yield $\left(950\right.$ to $\left.1100 \mu \mathrm{gml}^{-1}\right)$ was obtained in $1.0 \mathrm{~L}$ fermenter with working volume of $1.5 \mathrm{~L}$ at $28{ }^{\circ} \mathrm{C}$ with initial $\mathrm{pH}$ of 6.2 to 6.5 . The agitation and aeration were $300 \mathrm{rpm}$ and $0.5 \mathrm{LL}^{-1} \mathrm{~min}^{-1}$ respectively.

Keywords: Nocardia mediterranea ATCC 13865, Agitator, Carbohydrate, Rifamycin B, Fed-batch, Optimization.

Article Info: Received 28 May, 2017; Review Completed 10 July, 2017; Accepted 11 July, 2017; Available online 15 July, 2017

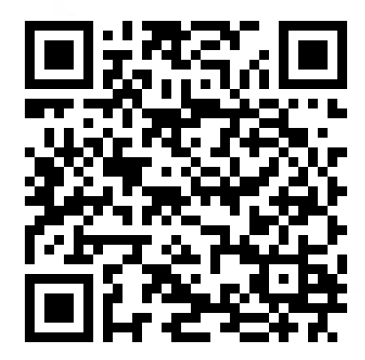

Cite this article as:

Niranjan SK, Kaushal C, Jain S.K., Optimization of rifamycin b using Nocardia mediterranea (atcc 13865) by fed batch mode in shake flasks, Journal of Drug Delivery and Therapeutics. 2017; 7(4):78-81

DOI: http://dx.doi.org/10.22270/jddt.v7i4.1469

*Address for Correspondence

Institute of pharmacy Shri Venkateshwara University, Gajraula, Uttar Pradesh, India,

E-mail: suneelniranjan3@gmail.com

\section{INTRODUCTION}

One of the purposes of fed-batching is to make the substrate(s) available to the microorganism at an optimum concentration for a longer period of time or at specified times of the process. In the fed-batch mode, gradual addition of concentrated additives, e.g. nutrients, takes place. Fed-batch cultures can be used for fermentation processes in which the products are either growth associated or non-growth associated. In the course of the development of the fermentation process for production of rifamycin $\mathrm{B}$, fed-batch fermentations have been developed in order to extend the production phase, where sources of sugar, organic and inorganic nitrogen were fed -batch wise or continuously ${ }^{1}$. The bacterial culture of Nocardia mediterranea ATCC 13865 was used for production of ant tubercular antibiotic rifamycin by submerged fermentation procedure. In previous (Ist paper reference). The culture was improved by sequential mutagenic treatment with NTG (N-methyl-N' -nitro-N-nitroso- guanidine) and U.V radiation. The mutant strain was designed as Nocardia Mediterranea M-120. Carbohydrates in the form of monosaccharide's and disaccharides were employed for the production of rifamycin. Among all sugars glucose $(9.5 \% \mathrm{w} / \mathrm{v})$ gave the maximum yield of antibiotic ${ }^{2-5}$.

\section{MATERIAL AND METHOD}

\section{Bacterial strains}

Nocardia mediterranea ATCC 13865 was obtained from American type culture collection centre, USA and maintained on agar slants of medium containing $\left(\mathrm{gl}^{-1}\right)$ peptone-6, yeast extract-3, beef extract-1.5, dextrose-1, 
agar-15,pH-6.6 . Used for production of antibiotic rifamycin.

\section{Stock culture}

Pure and high yielding culture of Nocardia mediterranea ATCC 13865 was used for the production of antibiotic, rifamycin B. The culture was maintained on MLsporulating agar medium (mineral base lactose medium) as described by figure 1 . The ingredients were dissolved in distilled water. The $\mathrm{pH}$ of the medium was adjusted with $\mathrm{NaOH}$ or $\mathrm{HC} 1$. All the media unless otherwise stated were autoclaved at $121^{\circ} \mathrm{C}$ for 15 minutes. Slants were incubated at $28^{\circ} \mathrm{C}$ for 5 days for sporulation and then stored in the refrigerator at $4{ }^{\circ} \mathrm{C}$ for further use (O.M., 2004). Sub culturing was made after every four night. The culture was improved by sequential mutagenic treatment with nitrosoguanidine (N.T.G) and UV irradiation and the selection was based on increasing concentrations of rifamycin B in shake flasks ${ }^{6,7}$.

\section{Fermentation medium}

The initial fermentation medium for fermentation experiments containing $\left(\mathrm{gl}^{-1}\right)$ Glucose- 94, Soybean meal- 10, Peanut meal- 21.4, $\mathrm{CaCO}_{3}-9.5, \mathrm{KH}_{2} \mathrm{PO}_{4}-0.4$, $\mathrm{MgSO}_{4} 7 \mathrm{H}_{2} 0$ - 1.0, Barbital- 2.0, Glucose- 70, Peptone30, Glycerol- 20, $\mathrm{CaCO}_{3}-8.0, \mathrm{KH}_{2} \mathrm{PO}_{4}-19, \mathrm{MgSO}_{4} 7 \mathrm{H}_{2} \mathrm{O}_{-}$ 1.0, Barbital- 2.0, $\left(\mathrm{NH}_{4}\right)_{2} \mathrm{SO}_{4^{-}}$3.0, $\left(\mathrm{NH}_{4}\right)_{2} \mathrm{SO}_{4^{-}} \quad 8.0$,
$\mathrm{CuSO}_{4} .5 \mathrm{H}_{2} \mathrm{O}-0.0165, \mathrm{ZnSO}_{4} .7 \mathrm{H}_{2} 0-0.004, \mathrm{FeSO}_{4} .2 \mathrm{H}_{2} 0-$ $0.002, \mathrm{MnSO}_{4} \cdot 4 \mathrm{H}_{2} 0-0.001$.was used and various other method as age and size inoculums, UV irradiation .Other chemical such as glucose, ammonium sulphate, $\mathrm{KH}_{2} \mathrm{PO}_{4}$ and calcium carbonate etc. were of analytical grade. Fermentation experiment were conducted in $250 \mathrm{ml}$. shake flask with $50 \mathrm{ml}$. medium for a period of 12 days by changing the various concentration of media component and optimizing the cultural condition of the strain to improve the rifamycin production ${ }^{10,11}$.

\section{RESULT AND DISCUSSION}

\section{Production of Rifamycin}

\section{Effect of incubation temperature}

The influence of incubation temperature on rifamycin B production was investigated by cultivating Nocardia mediterranea in medium M-6 at different levels of temperature. Initially rifamycin production was enhanced with the rise in temperature. The optimum temperature for maximum antibiotic production was found to be $29^{\circ} \mathrm{C}$. An increase or decrease further in the temperature reduced the yield of antibiotic indicating that the bacterium is sensitive to temperature in many reports the optimum temperature for rifamycin B fermentation is given as $29^{\circ} \mathrm{C}^{12}$.

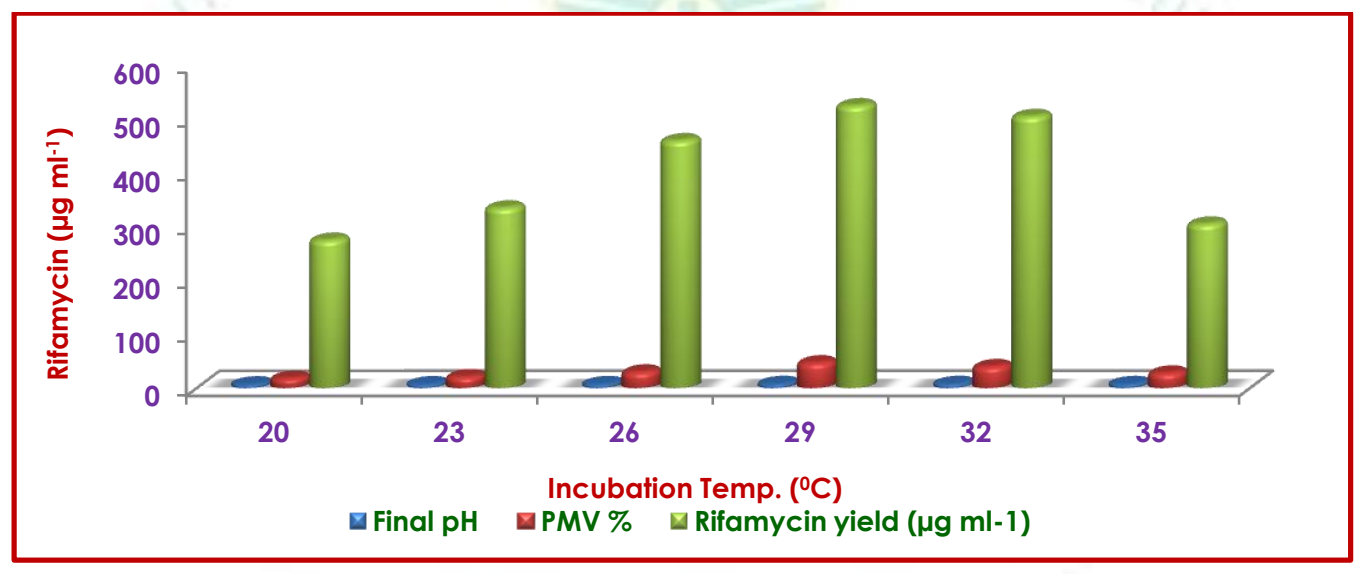

Figure 1: Effect of incubation temperature on the production of rifamycin

\section{Effect of aeration}

The availability of oxygen to the microbes during fermentation plays important role for the synthesis of secondary metabolites. In order to compare the effect of aeration on the bacterial cell mass and rifamycin production, the different volumes such as $25,50,75$, 100 , and $125 \mathrm{ml}$ of the medium M-6 was taken into 250 $\mathrm{ml}$ flask. After incubation the fermentation was carried out for 120 hours. The shake flasks used had the same size and form and shaking was done under the same conditions. The lesser the volume of the medium present in the flask, the higher was the oxygen supply to the culture. The rifamycin potency was slightly increased from 350 to $362 \mu \mathrm{gml}^{-1}$ when volume of the medium in flasks was changed from $25 \mathrm{ml}$ to $50 \mathrm{ml}$ and percent mycelia volume (PMV) varied from 24 to $26 \%$. Both the rifamycin production and cell biomass adversely affected when the volume was increased beyond 50 $\mathrm{ml} /$ flask $^{3}$.

The rifamycin yield was only $191 \mu \mathrm{gml}^{-1}$ and cell biomass formation was poor (PMV) when $125 \mathrm{ml}$ of the medium was present in the flask. The shaking of flasks on rotary mechanical shaker provided aeration for the microorganism. The rifamycin production was maximal when $50 \mathrm{ml}$ of fermentation medium was present in the flask. Further increase resulted in the volume in lowering the antibiotic production due to lesser agitation, which in turn resulted in to poor oxygen supply to the culture. The optimum volume of production medium $(50 \mathrm{ml} / 250 \mathrm{ml})$ flask is in accordance with the studies of $\mathrm{BM}^{4,8}$. 


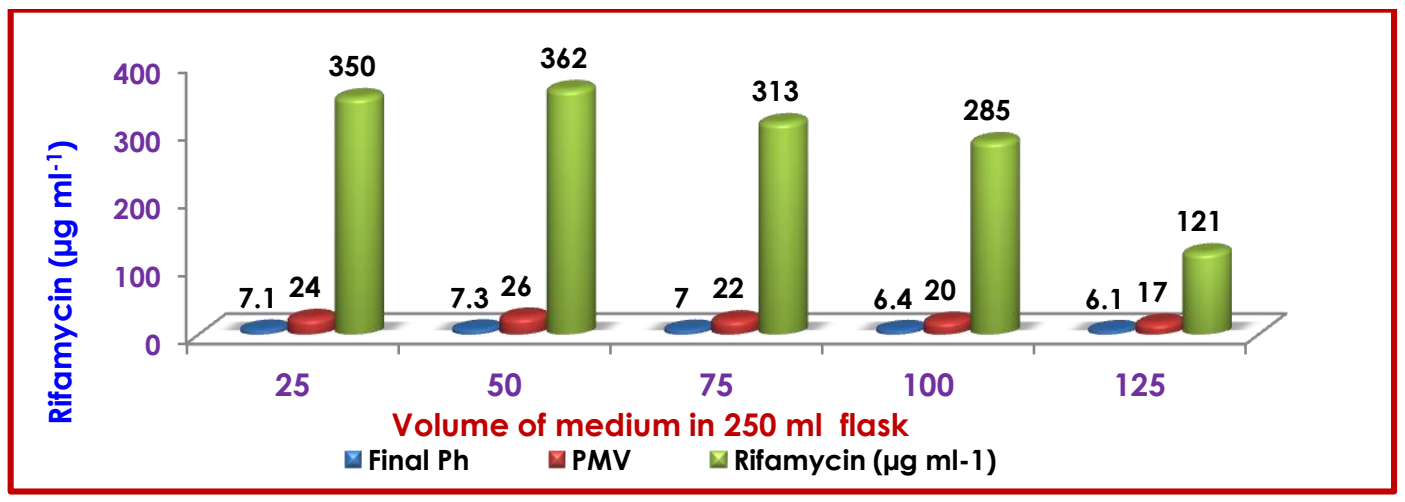

Figure 2: Effect of aeration on the production of rifamycin

\section{Effect of aeration and agitation}

The availability of oxygen to the microbes during fermentation is very critical for the synthesis of enzymes or metabolites. Only dissolved oxygen becomes available to the microbes for its propagation in metabolites formation. To investigate the effect of aeration on the production of antibiotic rifamycin $\mathrm{B}$, a series of batch cultures were run using Nocardia mediterranea M-120. The rate of agitation was set at 200, 300 and $500 \mathrm{rpm}$ with different rates aeration (1.0 to $\left.2.0 \mathrm{LL}^{-1} \mathrm{~min}^{-1}\right)^{9}$. During the course of fermentation, $\mathrm{pH}$, residual glucose, cell biomass and antibiotic potency were estimated. In this processes the optimum rifamycin yield (949 to $1100 \mu \mathrm{gml}^{-1}$ ) was obtained in 1.0 $\mathrm{L}$ fermenter with working volume of $1.5 \mathrm{~L}$ at $28^{\circ} \mathrm{C}$ with initial $\mathrm{pH}$ of 6.2 to 6.5 . The agitation and aeration were $300 \mathrm{rpm}$ and $1.0 \mathrm{LL}^{-1} \mathrm{~min}^{-1}$ respectively.

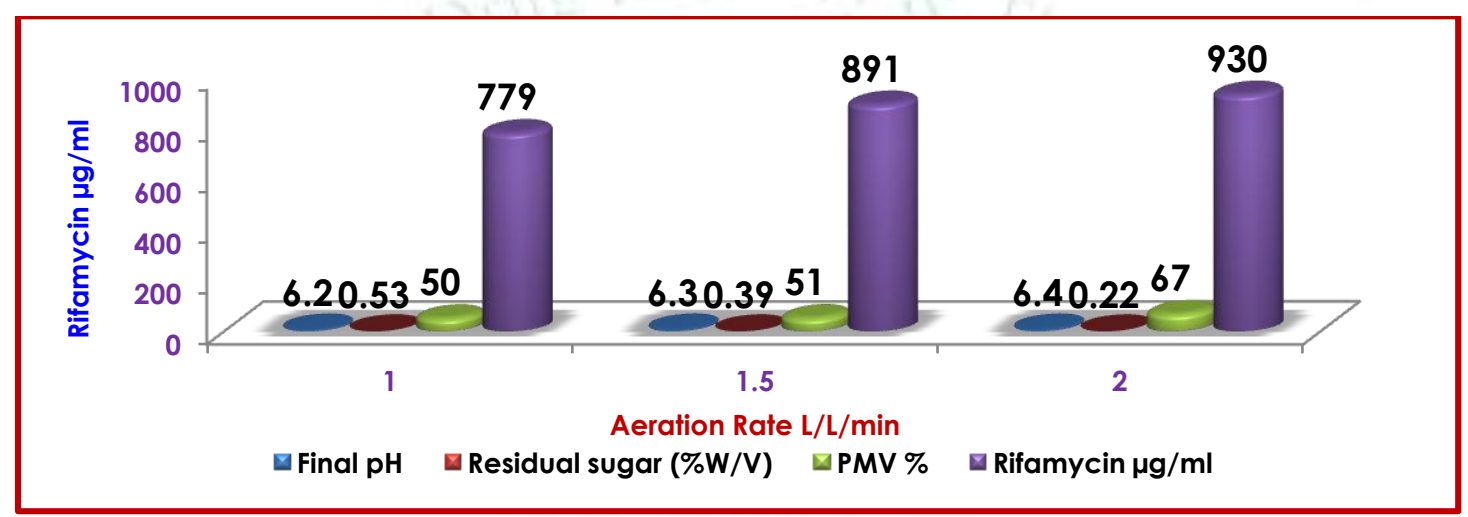

Figure 3: Effect of aeration on the production of Rifamycin B by nocardia mediterranea M-120 at $200 \mathrm{rpm}$

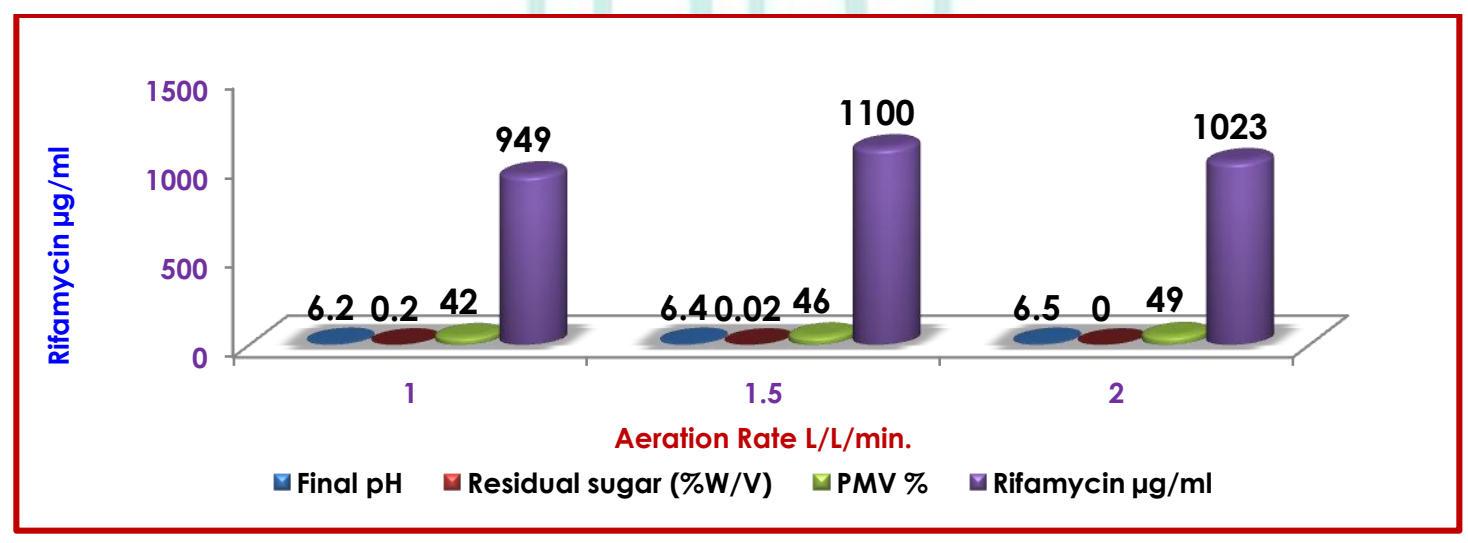

Figure 4: Effect of Aeration on the Production of Rifamycin B By Nocardia Mediterranea M-120 at 300 Rpm

\section{Effect of carbohydrates}

An adequate supply of the carbon energy source is critical for optimal growth and production formation. The culture Nocardia mediterranea M-120 was cultivated in the basal medium M-6 deleting glucose. The effect of different carbohydrates such as glucose, lactose, fructose, sucrose, maltose and glycerol etc on the production was investigated in the basal medium.
Each carbon source was added separately at a concentration of $5 \%, 7.5 \%$ and $10 \%(\mathrm{w} / \mathrm{v})$ to the fermentation medium before sterilization in all the experiments to investigate their effect on the rifamycin production. Glucose showed the highest production of antibiotic $\left(578 \mu \mathrm{gml}^{-1}\right)$. Fructose also stimulated the rifamycin production to a lesser extent as compared to glucose. The antibiotic activity was maximal in the

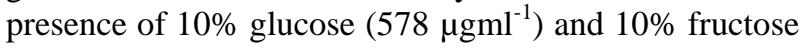


(489 $\mu \mathrm{gml}^{-1}$ ). While sucrose, sorbital, galactose and maltose were less effective.

Addition of xylose, lactose or starch even decreased the antibiotic production. The control basal medium without any sugar gave $138 \mu \mathrm{gml}^{-1}$ rifamycin B. It follows that defatted meals also provide nutrients both for bacterial growth and antibiotic production. The addition of sugar however, increases the synthesis of antibiotic.

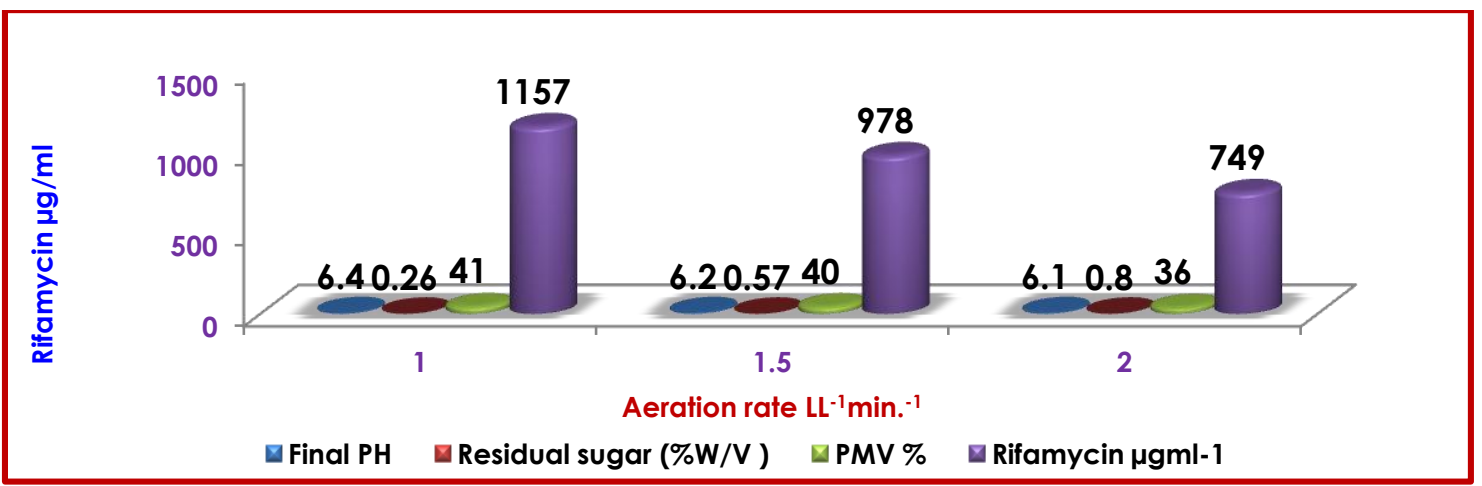

Figure 5: Effect of Aeration on the Production of Rifamycin B by Nocardia Mediterranea M-120 at 500 Rpm

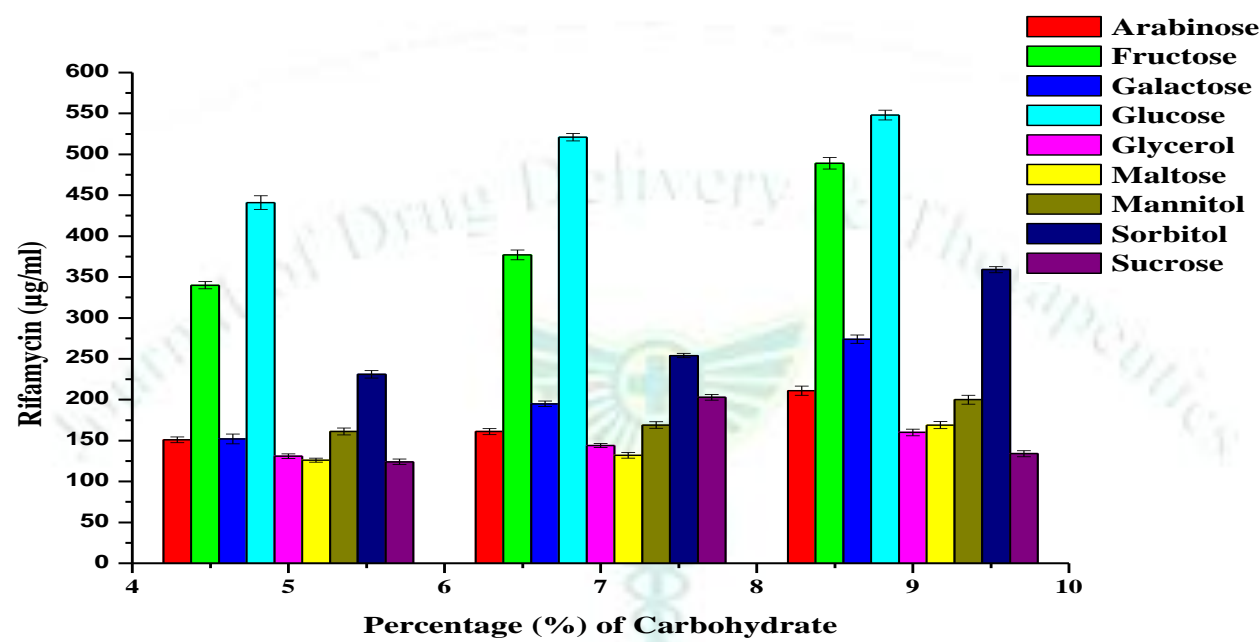

Figure 6: Effect of different carbohydrates on the production of rifamycin

\section{REFERENCES}

1. El-Tayeb, O.M., Hussein, M. M. M., Salama, A.A. and ElSedawy, "Optimization of industrial production of rifamycin B by Amycolatopsis mediterranei. III. Production in fed-batch mode in shake flask", African Journal of Biotechnology, 2004; 3 (8):387-394.

2. Bapat PM, Wangikar PP, "Optimization of Rifamycin B fermentation in shake flasks via a machine-learning-based approach", Biotechnol Bioeng, 2004; 86:201-208.

3. El Enshasy HA, El Baz AF, and Ammar EM. "Simultaneous production and decomposition of different Rifamycins during Amycolatopsis mediterranei growth in shake flask and in stirred tank bioreactor", Current Research and Educational Topics and Trends in Applied Microbiology A. Méndez-Vilas,Formatax (Ed.), 2005; 315-21

4. Heinz G. Floss and Tin-Wein Yu, "Rifamycin Mode of Action, Resistance, and Biosynthesis", Chemical Reviews, 2005; 105(2):621-32

5. El-Sedawy HF, Hussein MMM, Essam T, El-Tayeb OM, Mohammad FHA. "Scaling Up for the Industrial Production of Rifamycin B Fed-Batch Production Mode in Shake Flasks and Bench-Scale Fermentor", Ferment Technol,2007; 1(5):2167-72

6. Jin $\mathrm{ZH}$, Lin JP, Xu ZN, Cen PL. "Improvement of industryapplied rifamycin B-producing strain, Amycolatopsis mediterranei, by rational screening", J. Gen. Appl. Microbiol,2002; 48(6):329-334.
7. JIN Zhi-hua, LIN Jian-ping, CEN Pei-lin, "Scale-up of rifamycin B fermentation with Amycolatoposis", Mediterranei Journal of Zhejiang University science,2004; 5(12):1590-96

8. Mandali N, Girijashankar V, Ponamgi SPD, Peela S, Rao LV. "Rifamycin SV production using immobilized cells of Amycolatopsis mediterranei OVA5-E7 in different matrices", Journal of Chemical and Pharmaceutical Research, 2014; 6(9):298-306

9. Ates S, Elibol M, Mavituna F. "Production of actinorhodin by Streptomyces coelicolor in batch and fed-batch cultures", Science Direct, 2010; 32(4):273-278.

10. Xuan-Tien Doan, Srinivasan R, Bapat PM, Wangikar PP. "Detection of phase shifts in batch fermentation via statistical analysis of the online measurements: A case study with rifamycin B fermentation", Journal of Biotechnology,2007; 132(2):156-66

11. Xuan-Tien Doan, Srinivasan R, Bapat PM, Wangikar PP, "Detection of phase shifts in batch fermentation via statistical analysis of the online measurements: A case study with rifamycin B fermentation". Current Trends in Biotechnology and Pharmacy, 2010; 3(1):153-61

12. Y. Mahalaxmi, Ch. Subba Rao, G. Suvarnalaxmi, T. Satish, P. Sudhakar and R. S. Prakasham. "Rifamycin B Production Pattern in Nocardia RSP-3 Strain and Influence of Barbital on Antibiotic Production",Current Trends in Biotechnology and Pharmacy, 2008, 2 (1) 173-181. 